\title{
Prostate-Specific Antigen Testing among the Elderly in Community-Based Family Medicine Practices
}

\author{
Shawna V. Hudson, PhD, Pamela Obman-Strickland, PhD, Jeanne M. Ferrante, MD, \\ Grace Lu-Yao, PhD, A. John Orzano, MD, MPH, and Benjamin F. Crabtree, PhD
}

Background: Controversy surrounds prostate-specific antigen (PSA) testing for prostate cancer screening, especially among elderly men aged 75 and older. This study examines whether patient age results in differential use of PSA testing and if organizational attributes such as communication, stress, decision making, and practice history of change predict PSA testing among men aged 75 and older.

Methods: Data came from chart audits of 1149 men $\geq 50$ years old who were patients of 46 family medicine practices participating in 2 northeastern practice-based research networks. Surveys administered to clinicians and staff in each practice provide practice-level data. A stratified Cochran-MantelHaenszel test was applied to examine whether PSA testing decreased with age. Hierarchical logistic regression analyses determined characteristics associated with PSA testing for men $\geq 75$ years old.

Results: Comparable rates for annual PSA testing of $77.2 \%$ for men aged 50 to 74 years and $\mathbf{7 4 . 6 \%}$ for men $\geq 75$ years old were reported. The Cochran-Mantel-Haenszel test indicated no significant change in trend. Hierarchical models suggest that practice communication is the only organizational attribute that influences PSA testing for men 75 years of age or older (odds ratio, $5.04 ; P=.022$ ). Practices with higher communication scores (eg, promoted constructive work relationships and a team atmosphere between staff and clinicians) screened men aged 75 and older at lower rates than others.

Conclusions: Elderly men in community settings receive PSA testing at rates comparable to their younger counterparts even though major clinical practice guidelines discourage the practice for this population. Intraoffice practice interventions that target PSA testing to the most appropriate populations and focus on communication (both within the office and with patients) are needed. (J Am Board Fam Med 2009;22:257-65.)

Prostate cancer is the leading cause of new cancer cases and the second leading cause of cancer death among men in the United States. One in 6 American men will be diagnosed with prostate cancer during their lifetime. ${ }^{1}$ In 2007 there were an estimated 218,890 new cases and 27,050 deaths from prostate cancer. ${ }^{1}$ Controversy surrounds prostate cancer screening (ie, prostate-specific antigen [PSA] testing in conjunction with digital rectal examination [DRE]) because of a lack of definitive evidence about its effectiveness in improving clin-

This article was externally peer reviewed.

Submitted 26 June 2008; revised 27 October 2008; accepted 6 November 2008.

From the Cancer Institute of New Jersey, UMDNJ/Robert Wood Johnson Medical School, New Brunswick (SVH, JMF, GL-Y, BFC); the Department of Family Medicine, UMDNJ/Robert Wood Johnson Medical School, New Brunswick (SVH, PO-S, JMF, BFC); the Biometrics Division, UMDNJ School of Public Health, Piscataway (PO-S); and the New Hampshire Dartmouth Family Medicine Residency Program, Concord (AJO).

Funding: This research was conducted in conjunction with the New Jersey Family Medicine Research Network (NJFMRN), a shared resource of the Cancer Institute ical outcomes and reducing mortality. ${ }^{2,3}$ The US Preventive Services Task Force (USPSTF) does not recommend for or against prostate cancer screening; the American College of Physicians and the American College of Preventive Medicine endorse individualizing the decision to screen, whereas the American Cancer Society and the American Urological Association recommend offering the PSA test in conjunction with DREs annually beginning at age 50 to men who have a further life expectancy of at least 10 years. ${ }^{4-8}$

of New Jersey and the Eastern Pennsylvania Inquiry Collaborative Network (EPICnet). It was also supported by the Cancer Institute of New Jersey's Survey Research and Qualitative Methods Shared Resource. This research was supported through grants from the National Cancer Institute (K01 CA131500-01A1); National Heart, Blood and Lung Institute (R01 HL70800); the New Jersey Commission on Cancer Research (03-40-CCR-S0); and the Department of

Defense (DAMD 17-01-1-0755).

Conflict of interest: none declared.

Corresponding author: Shawna V. Hudson, $\mathrm{PhD}$, The Cancer Institute of New Jersey, 195 Little Albany Street, New Brunswick, NJ 08903-2681 (E-mail: hudsonsh@umdnj.edu). 
Surveys of primary care physicians suggest that PSA testing is routine practice for many. ${ }^{9-15} \mathrm{~Pa}-$ tient surveys show prostate cancer screening to be fairly common ${ }^{16}$ (more common than colorectal cancer screening, ${ }^{3,17}$ for which there are evidencebased screening recommendations). Published chart review studies conducted in primary care practices reported PSA testing rates of $25 \%$ to $40 \%$ in the 1990s. ${ }^{18,19}$ PSA testing was associated with patient factors $(>59$ years old, nonsmoking status, having private insurance, race) and physician factors (older physicians were more likely to screen, being in a practice with multiple physicians, readiness to change cancer screening behavior). ${ }^{10,18-20}$ A study using 2000 National Health Interview Survey data found the majority of PSA test recipients were nonHispanic white men aged 50 to 69 with relatively high levels of education, income, access to health care, and general health. ${ }^{16}$

Older patient age is also associated with PSA testing, ${ }^{18}$ yet there are few data that support clinical decisions to test men over the age of $75 .^{21-23}$ There are a number of concerns related to testing in this group. ${ }^{24}$ First, PSA tests cannot distinguish lethal versus nonlethal prostate cancer ${ }^{24,25}$; therefore, it is unclear who is likely to benefit from treatment. Second, although treatment with radical prostatectomy has recently been associated with moderate mortality reduction, ${ }^{26-28}$ it is unclear whether treatment results in significant increases in life$\operatorname{span}^{7,8}$ or quality of life. ${ }^{21,23,29}$ Therefore, there are a number of questions about the cost-benefit associated with testing and treatment that have led the USPSTF to issue a D ("do not screen") recommendation for men aged 75 and older. ${ }^{24}$

Nevertheless, several recent studies have found that men aged 75 and older routinely receive screening. ${ }^{30-32}$ Studies using physician-reported data from the 1999 to 2002 National Ambulatory Medical Care Survey reports PSA testing to be approximately $28 \%$ in men older than $75 .{ }^{32}$ One retrospective study of PSA testing in 7 New England Veteran Health Administration hospitals found a rate of $18 \%$ for men 75 years of age or older. ${ }^{30}$ Another study of outpatient visits in the 104 hospitals overseen by the US Department of Veterans' Affairs found decreasing rates of testing, starting with $56 \%$ for men ages 75 to $79,43 \%$ for men ages 80 to 84 , and $36 \%$ for men $\geq 85$ years old. ${ }^{31}$
Studies documenting self-reported PSA testing report comparable rates. Lu-Yao et $\mathrm{al}^{21}$ report PSA testing rates of $39 \%$ for men aged 75 to 79 and $24 \%$ for men $\geq 80$ years old in 2000 based on the National Health Interview Survey. Further, the authors indicated that approximately one-third of PSA tests were initiated for diagnostic purposes and that these tests were not included in the calculation of screening rates. Thus, it can be inferred that approximately two-thirds of PSA tests occurred for preventive prostate cancer screening. Several studies have suggested that PSA testing might be overused among elderly men ${ }^{21,31}$ and results in overdiagnosis. ${ }^{33}$ For example, among men aged 85 years and older, $34 \%$ in the best health had a PSA test compared with $36 \%$ in the worst health in a Veterans' Affairs study. ${ }^{31}$

Much of the existing literature on this topic come from data generated in private health care settings that serve a fraction of the American public. There is no published data on PSA testing in community-based primary care settings where the bulk of patients receive their care. In addition, there are no studies that examine how practice characteristics or organizational climate are associated with PSA testing. However, there is a substantial literature that suggests that office characteristics such as office practice structure ${ }^{34-37}$ and competing demands $s^{38-40}$ are associated with the delivery of preventive services ${ }^{34,35,41-45}$ and cancer screening. ${ }^{34-37}$ The purpose of this study was to provide an updated examination of PSA testing in community-based family medicine practices and to assess whether organizational factors are associated with PSA testing in elderly men $\geq 75$ years of age.

\section{Methods}

This study is based on a secondary analysis of data collected in a study of chronic disease management. We used cross-sectional data collected at baseline, from April 2003 through December 2004, from the quality improvement intervention study "Using Learning Teams for Reflective Adaptation" (ULTRA). The ULTRA study used a multimethod assessment process ${ }^{46}$ to inform a facilitated teambuilding intervention ${ }^{47}$ aimed at improving guideline adherence for multiple chronic diseases among 55 practices in New Jersey and Pennsylvania. Detailed information about sample recruitment has been previously published. ${ }^{48,49}$ This study focuses 
on 46 nonresidency community-based practices. The University of Medicine and Dentistry of New Jersey/Robert Wood Johnson Medical School Institutional Review Board approved this study.

\section{Data Collection}

Clinical outcome data were collected from medical records. Each participating practice generated lists of patients seen in their office during the previous 12 months based on billing codes for asthma, coronary artery disease, diabetes, and hypertension, as well as a list of current patients seen for any reason. Within each practice, 20 patients were randomly selected from each list. All patients were used when there were fewer than 20 patients per diagnosis code. For all male patients, nurse chart auditors from the research team noted the dates of PSA testing as well as age and other patient information. This analysis focused only on men included in the chart review who were at least 50 years of age $(n=$ 1149).

In addition to the medical record review, practice managers and lead physicians completed a 46item practice information form that solicited information about topics such as patient population (eg, payer mix, race/ethnicity); staff turnover; the use of clinical reminder and prevention systems; and implementation of electronic medical records. Practice employees (clinicians, nursing staff, and office staff) also completed a self-administered practice climate survey that included the Survey of Organizational Attributes for Primary Care (SOAPC). ${ }^{50}$ This survey took approximately 15 to 20 minutes to complete and responses were kept confidential. Surveys were distributed once and a replacement survey was provided 1 month later to nonresponders. Of 46 nonresidency practices, 28 practices had at least a $65 \%$ response rate among the practice staff and were used in the following analyses, which examine relationships between PSA testing patterns and organizational characteristics.

A total of 755 practice members were surveyed across the 28 practices. We examined multiple characteristics of nonresponders and responders for differences that may bias our findings. Nonresponders were similar to responders in terms of gender, years employed in the practice, and staff roles (ie, physicians versus nonphysicians and clinical versus office staff). There was a difference, however, in number of hours worked per week $\left(\chi^{2}\right.$ $=7.10 ; P=.0077)$. Part-time employees were less likely to respond than full-time employees $(57 \%$ vs $68 \%$, respectively). At the practice level, we examined practices excluded from the analysis because of the $65 \%$ cutoff and found no significant differences in a number of traits between those and the ones included in the analysis, including ownership (physicians versus other); type of practice (solo, single specialty group, and multispecialty group); and years under current ownership.

\section{Outcomes}

PSA testing was the primary outcome. Dates for the most recent PSA values and patients' last visits to the practice were recorded to determine whether testing occurred within the past 1,2 , or 5 years.

\section{Sociodemographic Correlates}

Sociodemographic variables considered included patient age; the number of visits within the last 2 years; the number of major comorbid conditions (including diabetes, asthma, hypertension, or a heart condition); and whether the patient had received cholesterol screening during the past year. Cholesterol screening was used to determine whether the PSA testing was occurring as part of a standard panel of tests. In addition, a number of practice level demographics were assessed, including practice size; the average number of years the practices had been in existence; and practice estimates of payer mix, race/ethnicity of the patient population, and office volume measured as the proportion of patient offices visits per physician clinician.

\section{Organizational Factors}

Organizational factors of interest in this study were assessed using the SOAPC, ${ }^{50}$ a validated instrument that examines practice organization in the primary care setting. Clinicians and staff members were asked to describe their level of agreement ( $1=$ strongly disagree, $5=$ strongly agree) with a series of statements designed to measure practice communication, decision-making models, stress, and the practice's history of change. ${ }^{50}$ The communications scale included 4 items $(\alpha=0.81)$ such as, "The staff and clinicians in this practice operate as a real team." This scale describes whether all members of the practice are able to work through problems as a team through discussion and consultation with one another. ${ }^{50}$ The decision-making scale included 8 items $(\alpha=0.88)$ such as, "The practice 
encourages staff input for making changes and improvements." The stress scale comprised 6 items $(\alpha=0.85)$ including "It's hard to make any changes in this practice because we're so busy seeing patients." History of change was measured by 3 items $(\alpha=0.73)$ including, "Our practice has changed in how everyone relates." High scores for these scales indicate better communication and decision-making practices that encourage input from all employees, a stressful/overwhelming workload, and numerous changes in the management and culture of the practice. ${ }^{50}$ Measures were constructed for practices that achieved a response rate of a $65 \%$ or higher.

\section{Analyses}

Descriptive statistics were calculated for patients and practices. Frequencies for categorical variables and means and standard deviations for continuous variables were reported.

Each patient in the study was classified according to whether they had received PSA testing within the last 1,2 , or 5 years. To examine the relationship between age and testing, initial tables compared age group (5-year increments from 50 to 90 and at least 90) to whether PSA testing was conducted. A stratified Cochran-Mantel-Haenszel $(\mathrm{CMH})$ test was applied to test for a decreasing trend in the rate of PSA testing for increasing ages in which the table was stratified with respect to practice membership.

Hierarchical logistic regression models examined whether particular practice or patient characteristics were associated with differential rates of PSA testing among those aged 75 years or older. Within these analyses, a binary response of whether each patient had received PSA testing within the last year was modeled using a logit link function and a binomial distribution. Random effects representing practice accounted for similarities between patients attending the same practice. For patients, we included as predictors fixed effects of patient age; the number of visits within the last 2 years; the number of major comorbid conditions (including diabetes, asthma, hypertension or a heart condition); and whether the patient had received cholesterol screening in the past year. For the practices, potential fixed effect predictors included in all models were the number years practice in existence, whether the practice was solo or group practice, and the average age of each practices'
Table 1. Community-Based Practice Characteristics (n =46)

\begin{tabular}{ll}
\hline Characteristic & Percent Mean (Range) \\
\hline Practice size & 26 \\
$\quad$ Solo practice & 74 \\
$\quad$ Group practice & $23(5-50)$ \\
Payer mix & $8(0-75)$ \\
$\quad$ Medicare & \\
$\quad$ Medicaid & 19 \\
Race/ethnicity of practice patients & 14 \\
$\quad$ Predominantly minority ( $>50 \%$ & 67 \\
$\quad$ of patients) & $10.43(0-30)$ \\
$\quad$ Mixed (30\% to 49\% of patients) & $55.73(18-93)$ \\
$\quad$ White ( $>70 \%$ of patients) & $65.05(50-93)$ \\
Years in practice (average n) & \\
Age of men in the practices & (average) \\
Age of men included in chart audit & (average)
\end{tabular}

patients. Because there were missing values for at least one of the practices, additional practice-level descriptors were added individually to the model to examine significance in an effort not to dilute power. These included office volume (number of office visits, number of clinicians); minority status of the practice; and percent of payer mix with Medicare or Medicaid, as well as organizational attributes measured by aggregated responses to the SOAPC (communication, decision making, stress, and history of change). All analyses implemented used the SAS/STAT software (SAS system for Windows, version 9.1.3, SAS Institute, Inc., Cary, NC).

\section{Results}

The majority of practices were group practices (74\%). Two thirds of the patient panel $(67 \%)$ in each practice was estimated to be white (see Table 1). Practices estimated that, on average, $23 \%$ of their patients received Medicare benefits compared with $8 \%$ who received Medicaid coverage. The average practice had been in existence 10.43 years (SD, 9.06 years). The average age of men in the practice was 55.73 years (SD, 15.96 years) and the average age of men who were included in this chart audit was 65.05 years (SD, 10.30 years).

The average rate of PSA testing within the past year was $76.68 \%$. Among men aged 50 to 74 and among those at least 75 years of age, these rates were $77.22 \%$ and $74.58 \%$, respectively. 
Table 2. Age Categories and Frequencies (\%) of Those with Prostate-Specific Antigen Testing*

\begin{tabular}{lllllllllll}
\hline & \multicolumn{7}{c}{ Age Category (years) } \\
\cline { 2 - 9 } & $50-54$ & $55-59$ & $60-64$ & $65-69$ & $70-74$ & $75-79$ & $80-84$ & $85-89$ & $\geq 90$ \\
\hline $\begin{array}{l}\text { Total } \\
\text { Screened during the past year }\end{array}$ & 195 & 236 & 183 & 138 & 161 & 111 & 82 & 32 & 11 \\
$\quad(\mathrm{n}[\%])$ \\
$\begin{array}{l}\text { Screened during the past 2 years } \\
(\mathrm{n}[\%])\end{array}$
\end{tabular}

${ }^{*} \chi^{2}$ testing for trend after stratifying by practice is 2.04 with 2 -sided $P=.15$ for 1 year; 0.73 with $P=.39$ for 2 years; and 0.29 with $P=.59$ for 5 years. Percentages are rounded to the nearest whole percent.

The CMH test indicated no significant trend in the rate of PSA testing depending on age (within the past year: $\chi^{2}=2.04$, degrees of freedom $=1$, $P=.15$; within the past 2 years: $\chi^{2}=0.73, P=.39$; within the past 5 years: $\chi^{2}=0.29, P=.59$ ). Table 2 provides the rates of PSA testing for each age category, summing over practices.

Table 3 provides results of the initial hierarchical model exploring predictors of PSA testing within the past year for those older than 75 . The only significant predictor was whether a patient had received cholesterol screening within the past year $(P=.012)$.

Table 4 contains significance of the additional organizational predictors, for which we had information about a subset of 28 practices. Only the organizational attribute labeled "Communication" is significant $(P=.022)$. The effect size is large with an odds ratio of 0.20 when comparing prac- tices at the $25^{\text {th }}$ and $75^{\text {th }}$ percentiles of communication. Thus, the odds of testing a patient within the past year were $80 \%$ smaller within a practice scoring at the $75^{\text {th }}$ percentile on communication relative to a practice scoring at the $25^{\text {th }}$ percentile.

\section{Discussion}

Data from this study provide further support to the existing literature that shows PSA testing is common in primary care practices ${ }^{9,11-15}$ and provides an updated look at PSA testing in communitybased family medicine practices. The average practice testing rate of $77 \%$ for men aged 50 to 74 observed in this study is higher than rates reported in earlier chart audit studies, ${ }^{18,19}$ but it is comparable with self-report data collected for New Jersey in the 2001 Behavioral Risk Factor Surveillance Study, which placed PSA testing rates between

Table 3. Odds Ratios Derived from the Multivariate Hierarchical Model Describing the Odds of Prostate-Specific Antigen Testing during the Last Year*

\begin{tabular}{lcc}
\hline & Odds Ratio (95\% CI) & $P$ \\
\hline Patient level & & .38 \\
Age (5-yr increments) & $1.19(0.80-1.76)$ & .17 \\
Visits within last 2 years (n) & $1.05(0.98-1.12)$ & .15 \\
Comorbid conditions ${ }^{\dagger}$ (n) & $0.74(0.49-1.11)$ & .012 \\
Cholesterol within last year & $2.42(1.22-4.81)$ & .52 \\
Practice level & & .36 \\
Solo vs group & $1.63(0.37-7.24)$ & .55 \\
Age of practice (5-yr increments) & $0.91(0.74-1.13)$ & $0.91(0.68-1.23)$ \\
Average patient age (5-yr increments) &
\end{tabular}

\footnotetext{
*236 patients, 41 practices.

${ }^{\dagger}$ Count of whether patient has diabetes, hypertension, a heart condition, and/or asthma (score $\left.=0,1, \ldots 4\right)$.

${ }^{\ddagger}$ Unadjusted values for odds ratio, CI, and $P$ are $2.10,1.10-4.02$, and .027 , respectively.
} 
Table 4. Odds Ratios Derived from the Hierarchical Model Describing the Odds of Prostate-Specific Antigen Testing during the Last Year*

\begin{tabular}{lccc}
\hline Practice-level Attributes & Practices (n) & Patients (n) & $P$ \\
\hline Office volume & 38 & 229 & .99 \\
Minority Status & 37 & 208 & .20 \\
Medicare & 38 & 222 & .84 \\
Medicaid & 34 & 194 & .20 \\
Communication ${ }^{\dagger}$ & 28 & 145 & .022 \\
Decision Making & 28 & 145 & .42 \\
Stress/Busyness & 28 & 145 & .18 \\
History of Change & 28 & 145 & .94 \\
\hline
\end{tabular}

*After controlling for age, no. of visits within last 2 years, no. of comorbid conditions, whether cholesterol screening was done within the past year, solo versus group practice, and age of practice and average patient age.

${ }^{\dagger}$ Comparing a practice at the $25^{\text {th }}$ and $75^{\text {th }}$ percentiles (a difference of 0.93 points), this has an odds ratio of 5.03 and a CI of 1.29-19.71. That is, the odds of prostate-specific antigen screening for a man 75 years of age or older in a practice at the $25^{\text {th }}$ percentile of "Communication" are 5.03 times the odds for a similar man in a practice at the $75^{\text {th }}$ percentile of "Communication."

$61 \%$ and $77 \% .^{3}$ Our testing rate of $75 \%$ among men $\geq 75$ years of age is higher than the rates of $18 \%^{30}-56 \%^{31}$ that are published in other studies. However, this is not totally unexpected given a recent study that found that family physicians were more likely to screen men aged $\geq 75$ than other primary care providers. ${ }^{10} \mathrm{We}$ hypothesize that increased awareness of prostate cancer from the early 1990s, when the original chart audit studies were conducted, and targeted public service announcements may account for the increase reported. In addition, the small number of men older than 75 as well as continued testing among men ages $\geq 75$ in community settings may also account for the rates observed.

This study found an initial association between PSA testing and cholesterol screening. This association became insignificant, however, when other organizational factors such as communication were examined in the analysis. Specifically, we found that practices with higher communication scores (eg, practices that promote constructive work relationships, promote a team atmosphere between staff and clinicians, and resolve conflict and tension) screened men aged $\geq 75$ at lower rates than others. We have seen in other studies that office systems and environment impact the delivery of preventive screening. ${ }^{34-36,41-45}$ Our data suggest that these conditions may also impact the provision of PSA testing. It is important that future studies examine the larger context in which preventive services are offered to better understand and address the organizational dynamics that contribute to observed practice prostate cancer screening rates.
This study highlights a practice that has been largely ignored: PSA testing of men $\geq 75$ years of age in community settings. Practice guidelines ${ }^{4-8}$ suggest that men older than 75 with limited life expectancy $(<10$ years) have little to gain from prostate cancer screening and PSA testing unless they have a particularly aggressive tumor. ${ }^{51} \mathrm{Al}$ though there are a handful of studies that associate radical prostatectomy with moderate mortality reduction $^{26-28}$ for localized prostate cancer, the larger body of literature suggests that treatment for elderly men neither substantially increases either lifespan ${ }^{7,8}$ nor quality of life. ${ }^{21,23,29}$ However, we found in this study (not unlike others ${ }^{10,16,31,52}$ ) that a surprisingly high proportion $(75 \%)$ of men older than 75 are screened. Lu Yao et $\mathrm{al}^{21}$ question the wisdom of screening men at such ages, citing little benefit and comparable life expectancy for men older than 70 who choose not to have treatment versus men who choose definitive treatment. The 2001 Institutes of Medicine report, Crossing the Quality Chasm: A New Health System for the 21 $1^{\text {st }}$ Century $^{53}$ articulated several aims for health care including that it be effective, patient centered, and efficient. With the new guideline from the USPSTF that gives a D ("do not screen") recommendation $^{24}$ for men 75 years of age and older, it is clear that there is a lack of evidence showing that aggressive prostate cancer screening and subsequent treatment for elderly men is either effective, patient centered, or efficient.

Although current guidelines recommend that prostate cancer screening occur within the context of informed decision making, ${ }^{4-8}$ there are a grow- 
ing number of studies documenting that informed decision making has yet to be incorporated as a routine part of primary care practice. ${ }^{16,54,55} \mathrm{Lu}-$ Yao et $\mathrm{al}^{21}$ report that $88 \%$ of elderly men ( 75 years of age and older) indicated that their doctor suggested that they have PSA testing, but fewer than two-thirds reported discussing both pros and cons of PSA testing with their physicians. Similarly, a study of community physicians found that physicians ordered PSA tests without discussing them with their patients, citing medical and legal liability concerns. ${ }^{54}$ During the time period in which our data were collected, there was much discussion along the East Coast about a heavily publicized case of malpractice that involved PSA testing that may have affected testing decisions. ${ }^{56,57}$ Data from our study and these others suggest that this is a research area in need of further study, with major implications for potential design of targeted interventions focused on prostate cancer screening.

Study findings should be interpreted while considering several potential limitations. First, the race of patients in this sample was largely unknown. Most medical records for patients in this study did not record patient race or ethnicity. Because we relied on chart data rather than self-report data, we were unable to examine the effects of patient race and ethnicity on PSA testing. Second, our outcome measure highlights PSA usage but does not provide a comprehensive look at prostate cancer screening. The measure does not include clinician use of DRE and does not distinguish between PSA testing that was initiated for diagnostic versus preventive screening purposes. The parent study did not include data about urologic problems or the cancer status of patients. Therefore, we could not distinguish between men who were being evaluated for lower urinary tract symptoms versus those undergoing prostate cancer screening. Although these are important limitations, guidelines from USP$\mathrm{STF}^{24}$ and the American Urological Association ${ }^{58}$ recommend against PSA testing for either purpose in elderly populations, calling into question its value for men whose natural lifespan is $<10$ years. Therefore, we suggest that it is important to examine the practice of PSA testing regardless of the reason for initiation (ie, preventive cancer screening, diagnosis, monitoring) among elderly populations.

Despite these limitations, data from this study are suggestive for interventions focused on PSA testing and prostate cancer screening in primary care settings. Much of the previous research on prostate cancer screening focuses on understanding patient and physician characteristics that influence screening decisions. It is unclear what is driving decision-making processes about who receives PSA testing and prostate cancer screening in primary care practices. Is this a decision made unilaterally by physicians or nurse practitioners on an individual basis? Are there standing orders and, if so, how are they tailored? Are laboratories generating this data as part of a routine blood work panel? How does the patient's wish impact these processes? We suggest that future research is needed to better understand the circumstances in which PSA testing and prostate cancer screening is initiated in primary care settings so that intervention studies focused on providing testing for the most appropriate populations can be better calibrated to address patient, physician, and organization correlates of testing.

\section{References}

1. Jemal A, Siegel R, Ward E, Murray T, Xu J, Thun MJ. Cancer statistics, 2007. CA Cancer J Clin 2007; 57:43-66.

2. Ransohoff DF, McNaughton Collins M, Fowler FJ. Why is prostate cancer screening so common when the evidence is so uncertain? A system without negative feedback. Am J Med 2002;113:663-7.

3. Sirovich BE, Schwartz LM, Woloshin S. Screening men for prostate and colorectal cancer in the United States: does practice reflect the evidence? JAMA 2003;289:1414-20.

4. Screening for prostate cancer. American College of Physicians. Ann Intern Med 1997;126:480-4.

5. Carroll P, Coley C, McLeod D, et al. Prostatespecific antigen best practice policy-part I: early detection and diagnosis of prostate cancer. Urology 2001;57:217-24.

6. Ferrini R, Woolf SH. American College of Preventive Medicine practice policy. Screening for prostate cancer in American men. Am J Prev Med 1998;15: 81-4.

7. Smith RA, Cokkinides V, Eyre HJ. American Cancer Society Guidelines for the Early Detection of Cancer, 2005. CA Cancer J Clin 2005;55:31-44.

8. US Preventive Services Task Force. Screening for prostate cancer: recommendation and rationale. Ann Intern Med 2002;137:915-6.

9. Austin OJ, Valente S, Hasse LA, Kues JR. Determinants of prostate-specific antigen test use in prostate cancer screening by primary care physicians. Arch Fam Med 1997;6:453-8.

10. Konety BR, Sharp VJ, Verma M, Williams RD. 
Practice patterns in screening and management of prostate cancer in elderly men. Urology 2006;68: 1051-6.

11. Edlefsen KL, Mandelson MT, McIntosh MW, Andersen MR, Wagner EH, Urban N. Prostatespecific antigen for prostate cancer screening. Do physician characteristics affect its use? Am J Prev Med 1999;17:87-90.

12. Hoffman RM, Papenfuss MR, Buller DB, Moon TE. Attitudes and practices of primary care physicians for prostate cancer screening. Am J Prev Med 1996;12: 277-81.

13. Lawson DA, Simoes EJ, Sharp D, et al. Prostate cancer screening-a physician survey in Missouri. J Community Health 1998;23:347-58.

14. Purvis Cooper C, Merritt TL, Ross LE, John LV, Jorgensen CM. To screen or not to screen, when clinical guidelines disagree: primary care physicians' use of the PSA test. Prev Med 2004;38:182-91.

15. Voss JD, Schectman JM. Prostate cancer screening practices and beliefs [see comment]. J Gen Intern Med 2001;16:831-7.

16. Han PK, Coates RJ, Uhler RJ, Breen N. Decision making in prostate-specific antigen screening $\mathrm{Na}$ tional Health Interview Survey, 2000. Am J Prev Med 2006;30:394-404.

17. Carlos RC, Underwood W 3rd, Fendrick AM, Bernstein SJ. Behavioral associations between prostate and colon cancer screening. J Am Coll Surg 2005; 200:216-23.

18. Moran WP, Cohen SJ, Preisser JS, Wofford JL, Shelton BJ, McClatchey MW. Factors influencing use of the prostate-specific antigen screening test in primary care. Am J Manag Care 2000;6:315-24.

19. Williams RB, Boles M, Johnson RE. Use of prostatespecific antigen for prostate cancer screening in primary care practice [see comment]. Arch Fam Med 1995;4:311-5.

20. Gilligan T, Wang PS, Levin R, Kantoff PW, Avorn $\mathrm{J}$. Racial differences in screening for prostate cancer in the elderly. Arch Intern Med 2004;164:1858-64.

21. Lu-Yao G, Stukel TA, Yao SL. Prostate-specific antigen screening in elderly men. J Natl Cancer Inst 2003;95:1792-7.

22. Lu-Yao GL, Barry MJ, Albertsen PC, Yao SL. Outcomes of treatment vs observation of localized prostate cancer in elderly men. JAMA 2007;297:1651; author reply 1652-3.

23. Yao SL, Lu-Yao G. Understanding and appreciating overdiagnosis in the PSA era. J Natl Cancer Inst 2002;94:958-60.

24. US Preventive Services Task Force. Screening for prostate cancer: US Preventive Services Task Force recommendation statement. Ann Intern Med 2008; 149:185-91.

25. Fall K, Garmo H, Andren O, et al. Prostate-specific antigen levels as a predictor of lethal prostate cancer. J Natl Cancer Inst 2007;99:526-32.
26. Bill-Axelson A, Holmberg L, Ruutu M, et al. Radical prostatectomy versus watchful waiting in early prostate cancer. N Engl J Med 2005;352:1977-84.

27. Wong YN, Mitra N, Hudes G, et al. Survival associated with treatment vs observation of localized prostate cancer in elderly men. JAMA 2006;296: 2683-93.

28. Holmberg L, Bill-Axelson A, Helgesen F, et al. A randomized trial comparing radical prostatectomy with watchful waiting in early prostate cancer. N Engl J Med 2002;347:781-9.

29. Lu-Yao GL, Friedman M, Yao SL. Use of radical prostatectomy among Medicare beneficiaries before and after the introduction of prostate specific antigen testing. J Urol 1997;157:2219-22.

30. Kerfoot BP, Holmberg EF, Lawler EV, Krupat E, Conlin PR. Practitioner-level determinants of inappropriate prostate-specific antigen screening. Arch Intern Med 2007;167:1367-72.

31. Walter LC, Bertenthal D, Lindquist K, Konety BR. PSA screening among elderly men with limited life expectancies. JAMA 2006;296:2336-42.

32. Scales CD, Jr., Curtis LH, Norris RD, Schulman KA, Albala DM, Moul JW. Prostate specific antigen testing in men older than 75 years in the United States. J Urol 2006;176:511-4.

33. Draisma G, Boer R, Otto SJ, et al. Lead times and Overdetection due to prostate-specific antigen screening: estimates from the European Randomized Study of Screening for Prostate Cancer. J Natl Cancer Inst 2003;95:868-78.

34. Dickey LL, Kamerow DB. Primary care physicians' use of office resources in the provision of preventive care. Arch Fam Med 1996;5:399-404.

35. Dietrich AJ, Carney PA, Winchell CW, Sox CH, Reed SC. An office systems approach to cancer prevention in primary care. Cancer Pract 1997;5:37581.

36. Hudson SV, Ohman-Strickland P, Cunningham R, Ferrante JM, Hahn K, Crabtree BF. The effects of teamwork and system support on colorectal cancer screening in primary care practices. Cancer Detect Prev 2007;31:417-23.

37. Dietrich AJ, O'Connor GT, Keller A, Carney PA, Levy D, Whaley FS. Cancer: improving early detection and prevention. A community practice randomised trial. BMJ 1992;304:687-91.

38. Jaen CR, McIlvain H, Pol L, Phillips RL Jr, Flocke $\mathrm{S}$, Crabtree BF. Tailoring tobacco counseling to the competing demands in the clinical encounter. J Fam Pract 2001;50:859-63.

39. Jaen CR, Stange KC, Nutting PA. Competing demands of primary care: a model for the delivery of clinical preventive services. J Fam Pract 1994;38: $166-71$

40. Jaen CR, Stange KC, Tumiel LM, Nutting P. Missed opportunities for prevention: smoking cessa- 
tion counseling and the competing demands of practice. J Fam Pract 1997;45:348-54.

41. Carney PA, Dietrich AJ, Keller A, Landgraf J, O'Connor GT. Tools, teamwork, and tenacity: an office system for cancer prevention. J Fam Pract 1992;35:388-94.

42. Carpiano RM, Flocke SA, Frank SH, Stange KC. Tools, teamwork, and tenacity: an examination of family practice office system influences on preventive service delivery. Prev Med 2003;36:131-40.

43. Crabtree BF, Miller WL, Aita VA, Flocke SA, Stange KC. Primary care practice organization and preventive services delivery: a qualitative analysis. J Fam Pract 1998;46:403-9.

44. Griffith HM, Rahman MI. Implementing the Put Prevention into Practice program. Nurse Pract 1994;19:12, 15-9.

45. Stange KC. One size doesn't fit all. Multimethod research yields new insights into interventions to increase prevention in family practice. J Fam Pract 1996;43:358-60.

46. Crabtree BF, Miller WL, Stange KC. Understanding practice from the ground up. J Fam Pract 2001; 50:881-7.

47. Stroebel CK, McDaniel RR Jr, Crabtree BF, Miller WL, Nutting PA, Stange KC. How complexity science can inform a reflective process for improvement in primary care practices. Jt Comm J Qual Patient Saf 2005;31:438-46.

48. Hudson SV, Harris-Haywood S, Stange KC, Orzano AJ, Crabtree BF. Recruiting minority primary care practices into practice-based research. Med Care 2006;44:696-700.

49. Orzano AJ, Scott J, Hudson SV, et al. Strategies for conducting complex clinical trials in diverse community practices. Med Care 2007;45:1221-6.

50. Ohman-Strickland PA, John Orzano A, Nutting PA, et al. Measuring organizational attributes of primary care practices: development of a new instrument. Health Serv Res 2007;42:1257-73.

51. Kawachi MH, Bahnson RR, Barry M, et al. Prostate cancer early detection. Clinical practice guidelines in oncology. J Natl Compr Canc Netw 2007;5:714-36.

52. Ross LE, Coates RJ, Breen N, Uhler RJ, Potosky AL, Blackman D. Prostate-specific antigen test use reported in the 2000 National Health Interview Survey. Prev Med 2004;38:732-44.

53. Institutes of Medicine. Committee on Quality of Health Care in America. Crossing the quality chasm: a new health system for the 21st century. Washington, D.C.: National Academy Press; 2001.

54. Guerra CE, Jacobs SE, Holmes JH, Shea JA. Are physicians discussing prostate cancer screening with their patients and why or why not? A pilot study. J Gen Intern Med 2007;22:901-7.

55. Lamplugh M, Gilmore P, Quinlan T, Cornford P. PSA testing: are patients aware of what lies ahead? Ann R Coll Surg Engl 2006;88:284-8.

56. Krist AH, Woolf SH, Johnson RE. How physicians approach prostate cancer screening before and after losing a lawsuit. Ann Fam Med 2007;5:120-5.

57. Merenstein D. A piece of my mind. Winners and losers. JAMA 2004;291:15-6.

58. American Urological Association. Guideline on the management of benign prostatic hyperplasia (BPH). 2003, updated 2006. Available at http://www.auanet. org/content/guidelines-and-quality-care/clinicalguidelines.cfm. Accessed 18 March 2009. 